\title{
Study on the Status Quo and Influencing Factors of Service Quality of Public Pension Agencies in Five Counties and Cities in Xinjiang Province
}

\author{
Jingjing Fan \\ Medical School \\ Shihezi University \\ Shihezi, China 832000
}

\author{
Xinhui $\mathrm{Li}^{*}$ \\ Medical School \\ Shihezi University \\ Shihezi, China 832000 \\ *Corresponding Author
}

\begin{abstract}
Objective: This study understands the status quo of service quality of public pension institutions in Xinjiang, explore influencing factors and provide references for improving the service quality of public pension institutions. Methods: from August 2017 to May 1818, a combination of typical sampling and random cluster sampling was used in five counties of Shihezi, Aksu, Manas, Wensu and Ruoqiang in Xinjiang. A total of 274 elderly people in public pension institutions conducted face-to-face questionnaire surveys. Results: The total satisfaction score of service quality of public pension institutions in Xinjiang was 75.96 \pm 11.46 , and the four dimensions from high to low were service environment, life care, spiritual entertainment, medical care. Ethnicity, type of old people, and occupation had a significant effect on the satisfaction of elderly services $(P<0.05)$. The interview found that the elderly living in the home are satisfied with the internal environment of the old-age care institution. They paid more attention to the quality of the aged care service, especially medical services. Conclusion: The overall satisfaction rate of the elderly in the public pension institutions is better, but it needs to be strengthened in the medical care service. The nationality, the type and the occupation of the elderly live in the pension institution are the influencing factors of the service quality of the pension institutions. Therefore, the evaluation of service quality includes not only objective factors but also the individual differences of the elderly affect the satisfaction of service quality to a large extent. The pension institutions should consider the expectations and needs of service users when providing the aged care services, so as to improve the service quality of the aged care institutions.
\end{abstract}

Keywords-public pension institutions; quality of service; influence factors

\section{INTRODUCTION}

In response to the increasing population aging and the weakening of family pension function, during the "Twelfth Five-Year Plan" period, under the support and guidance of the national pension policy, the scale and number of old-age care institutions have increased sharply. The situation of "a bed is hard to find" is basically reversed. In 2016, the government document on "Several Opinions on Comprehensively Opening the Aged Services Market to
Improve the Quality of Endowment Services" was released, it proposed that by 2020 , the service quality of the aged care service industry will be significantly improved, and the satisfaction of the people will be significantly improved. Since then, the focus of the development of old-age care institutions has been changed to improve service quality [1] The public pension institution has the richest experience in providing for the elderly. It plays a fundamental, exemplary and tactical role for all kinds of old-age care institutions, and plays an important role in the service quality construction of the old-age care institutions. However, with the comprehensive liberalization of the old-age service market, social capital has entered the old-age service industry, and the old-age industry has shown a diversified development pattern. The development of public-age care institutions face challenges. According to the latest data, there are 560 oldage care institutions and 41,914 beds in Xinjiang Uygur Autonomous Region, including 460 public pension institutions and 29,600 beds, which still account for a large proportion in the old-age care institutions in the region [2]. In order to promote the development of the old-age care institutions in Xinjiang, scholars have also explored the oldage care institutions in Xinjiang from different aspects, but the research on service quality has not been reported. As an economically underdeveloped and multi-ethnic area, the quality of service provided by public pension institutions has become an issue that needs to be understood and analyzed. In this context, this study is based on the perspective of the demand side of receiving pension services, and conducts a questionnaire survey on the elderly in public pension institutions to understand the status of service quality of public pension institutions in five counties and cities in Xinjiang, and explore the influencing factors, Which can provide direction for service improvement of public pension institutions.

\section{OBJECTS AND METHODS}

\section{A. Objects}

A combination of typical sampling and random cluster sampling is used to determine the five counties in Shihezi 
and Manas counties in northern Xinjiang, Aksu, Wensu and Ruoyi in southern Xinjiang as sample areas. A total of 5 public pension institutions conducted on-the-spot investigations. The elderly were selected only if they had lived in the public pension institutions for over one month, and had sufficient cognitive ability to answer the questionnaire.

\section{B. Methods}

1) Questionnaire survey method: From August 2017 to May 1818, the researcher selected investigators who are proficient in Chinese and Uighur and unified training. After obtaining the consent of the research subjects, the investigators conducted a questionnaire survey on the elderly in a face-to-face manner. The questionnaire was designed based on the SERVPERF scale and referenced to the questionnaire prepared by Jing Jie [3]. The questionnaire consisted of two parts; one was general information about the elderly, including gender, ethnicity, age, and education level, occupation, and health status. The other was the satisfaction evaluation of the service quality of the elderly, including 20 items in the service environment, life care, medical care and spiritual entertainment. Each item used a 5-point scoring method, with 1 to 5 points representing "very dissatisfied" to "very satisfied", the score ranged from 20 to 100 points. The higher is the score, the stronger is the satisfaction. The investigator issued a questionnaire together to explain the precautions. After the investigation object is completed, it would be recovered on the spot. A total of 274 questionnaires were distributed and 274 valid questionnaires were returned. The effective rate of the questionnaire was $100 \%$.

2) Statistical analysis: Data was entered using EpiData 3.1, and statistical analysis was performed using SPSS 17.0 statistical software. Quantitative data were statistically analyzed, t-test, analysis of variance, and multiple stepwise regression for statistical analysis.

\section{Results}

1) Sample characteristics: In this study, 274 elderly participated in the study, 206 were Han (75.3 percent), 68 were Uygur (24.7 percent), 147 were male (53.6 percent), of which 47.4 were female. The participants' mean age was 76.5 years old. Concerning educational level, 69.7 percent were in primary school and below, 28.8 percent were in junior and high school and 1.5 percent were in junior college and above. In terms of the elderly profession, 78 respondents were staff members (28.4 percent), 37 respondents were self-employed households (13.5 percent), 125 respondents were farmers (45.6 percent), 34 respondents were unemployed or unemployed (12.5 percent). In addition, regarding the physical condition, 24.7, 43.3, 32 percent of respondents reported that they were in good physical condition, in general and in difference. Regarding the degree of self-care, the elderly were completely self-care were 219 (79.9 percent) and half-disabled were 55 (20.1 percent). The old type was divided into two categories, 143 respondents were government-funded elderly, and 131 respondents were self-funded elderly.

2) Status of service quality of public pension institutions: The overall satisfaction score of the elderly in the service environment, living care, medical care and mental recreation was 75.96(SD 11.16). Service environment dimension has the highest score that was 20.53 (SD 3.50). Medical care dimension score was 17.64( SD 3.89), which is the lowest. All dimension entries were all above 3.5 points, and in a "satisfactory" grade, as shown in "Table I".

TABle I. Satisfaction Scores of Service Quality of Public Pension Institutions（N=274）

\begin{tabular}{|c|l|l|l|}
\hline Dimension & \multicolumn{1}{|c|}{ Dimension Score Range } & Dimension Equalization & Item Average \\
\hline Service environment & $7-25$ & $20.53 \pm 3.50$ & $4.11 \pm 0.88$ \\
\hline Life care & $13-25$ & $19.54 \pm 3.46$ & $3.91 \pm 0.09$ \\
\hline Medical care & $6-25$ & $17.64 \pm 3.89$ & $3.52 \pm 0.11$ \\
\hline Spiritual entertainment & $9-25$ & $18.29 \pm 4.01$ & $3.66 \pm 0.09$ \\
\hline Total score & $46-25$ & $75.96 \pm 11.46$ & $3.79 \pm 0.04$ \\
\hline
\end{tabular}

\section{Single Factor Analysis of Service Quality of Public Pension Institutions}

The service quality satisfaction score was the dependent variable and the general information of the elderly was the independent variable. Univariate analysis showed that the quality of the service quality of the elderly in different demographics, age, education level, occupation, old age type, and self-care ability was statistically significant $(\mathrm{P}<0.05)$, as shown in "Table II".

TABle II. Single Factor Analysis of Service Quality of Public Pension Institutions（N=274）

\begin{tabular}{|c|l|l|l|c|}
\hline Variable & & \multicolumn{1}{|c|}{ Satisfaction score } & \multicolumn{1}{|l|}{ Z/X2 } & P \\
\hline gender & male & $75.06 \pm 11.20$ & -0.72 & 0.472 \\
\hline & Female & $77.00 \pm 11.71$ & & \\
\hline Nationality & Han nationality & $73.69 \pm 12.96$ & $-8.84^{\mathrm{a}}$ & $0.000^{* *}$ \\
\hline $\boldsymbol{A g} \boldsymbol{e}$ & Uighur & $78.55 \pm 4.17$ & & \\
\hline & $60-69$ & $88.65 \pm 15.70$ & $19.244^{\mathrm{b}}$ & $0.000^{* *}$ \\
\hline & $70-79$ & $78.40 \pm 18.48$ & & \\
\hline & $80-89$ & $77.85 \pm 16.49$ & & \\
\hline
\end{tabular}




\begin{tabular}{|c|c|c|c|c|}
\hline Variable & & Satisfaction score & $\mathbf{Z} / \mathbf{X} 2$ & $\mathbf{P}$ \\
\hline Age & $\geq 90$ & $78.10 \pm 17.35$ & & \\
\hline \multirow[t]{2}{*}{ Marital status } & Married & $73.60 \pm 13.56$ & 0.813 & 0.43 \\
\hline & Non-married & $75.82 \pm 10.15$ & & \\
\hline \multirow{4}{*}{ Educational level } & Elementary school and below & $75.21 \pm 11.91$ & $16.104^{b}$ & $0.003 * *$ \\
\hline & junior high school & $76.39 \pm 9.75$ & & \\
\hline & High school/secondary school & $81.00 \pm 11.27$ & & \\
\hline & College and above & $85.66 \pm 4.72$ & & \\
\hline \multirow[t]{5}{*}{ Career } & Institution staff & $77.09 \pm 10.43$ & $16.10^{\mathrm{b}}$ & $0.003 * *$ \\
\hline & Private enterprise unit staff & $76.92 \pm 12.83$ & & \\
\hline & Self-employed households & $81.23 \pm 10.60$ & & \\
\hline & Farmer & $74.12 \pm 1.35$ & & \\
\hline & Unemployment or unemployment & $77.42 \pm 11.37$ & & \\
\hline \multirow[t]{5}{*}{ Economic status } & Ample & $81.35 \pm 9.89$ & 9.65 & 0.057 \\
\hline & Slight balance & $76.64 \pm 10.89$ & & \\
\hline & Basically maintain & $73.06 \pm 11.18$ & & \\
\hline & More nervous & $71.65 \pm 11.20$ & & \\
\hline & very nervous & $72.00 \pm 13.36$ & & \\
\hline \multirow[t]{5}{*}{ Physical conditions } & it is good & $73.47 \pm 13.68$ & 1.236 & 0.872 \\
\hline & better & $76.06 \pm 10.63$ & & \\
\hline & general & $74.76 \pm 11.39$ & & \\
\hline & Poor & $70.75 \pm 11.18$ & & \\
\hline & difference & $67.87 \pm 13.04$ & & \\
\hline \multirow[t]{2}{*}{ Self-care ability } & Fully self-care & $71.20 \pm 12.19$ & $-4.396^{\mathrm{a}}$ & $0.000 * *$ \\
\hline & Semi-disabled & $77.37 \pm 8.03$ & & \\
\hline \multirow[t]{2}{*}{ Type } & Government funded elderly & $73.69 \pm 9.18$ & $-6.124^{\mathrm{a}}$ & $0.000 * *$ \\
\hline & Self-funded elderly & $77.054 \pm 12.28$ & & \\
\hline
\end{tabular}

\section{E. Multi-factor Analysis of Service Quality of Public \\ Pension Institutions}

The multivariate stepwise regression model took the service quality satisfaction score as the dependent variable, and the Stepwise method selected the meaningful variable after the univariate analysis as the independent variable for multivariate analysis. The binary categorical variable was treated as the dummy variable. The multivariate stepwise regression analysis results showed that the nationality, the type of the elderly, and the occupation were the influencing factors of the service quality of the old-age care institutions $(\mathrm{P}<0.05)$. The total variation of the dependent variables could be explained by 46 percent of the independent variables in the regression model, as shown in "Table III".

TABle III. Multi-Factor Analysis of Service Quality of Public Pension Institutions (N=274)

\begin{tabular}{|c|l|l|l|l|l|}
\hline Variable & \multicolumn{1}{|c|}{ B } & \multicolumn{1}{|c|}{ Beta } & \multicolumn{1}{c|}{ t } & p \\
\hline Constant term & 47.081 & 1.501 & - & 15.348 & 0.000 \\
\hline Nationality & 4.785 & 0.392 & 0.835 & 3.464 & 0.000 \\
\hline Old type & -3.739 & 0.352 & -0.226 & -2.736 & 0.000 \\
\hline Career & & & & & \\
\hline Farmer & -1.635 & 0.248 & 0.192 & -1.886 & 0.018 \\
\hline Felf-employed households & 3.667 & 0.369 & 0.152 & 2.073 & 0.039 \\
\hline
\end{tabular}

\section{DISCUSSION}

\section{A. Analysis of the Status Quo of Service Quality of Public Pension Agencies in Xinjiang Province}

The old-age care institutions support the elderly as the direct recipients of the services. Their satisfaction is an important indicator to measure the quality of the service of the aged care institutions. The developed provinces and cities in China have successively carried out the evaluation of the satisfaction of the institution's pension. The Ministry of Civil Affairs and the National Standards Committee jointly have organized the national standards for the evaluation of service satisfaction of the aged care institutions. All of which indicate that the satisfaction survey of the elderly in the old- age institutions is an effective way to reflect the quality of the service of the aged care institutions. The results of this study show that the satisfaction rate of service quality of the elderly is divided into 3.77 points, which is in the middleupper level. The four dimensions of the scores from high to low are service environment, life care, spiritual entertainment and medical care, as shown in Table I. The results of the study are different from the results of the highest evaluation of the quality of medical care services provided by Wang Lijian in Suzhou's old-age care institutions [4]. The facilities and equipment of the old-age care institutions are an important part of the service environment and are the material conditions for ensuring the care of the nursing staff and the medical care [5]. Field research find that the basic life, cultural entertainment and 
safety support facilities of the five public pension institutions are at a high level, reaching the national standard for the "Architectural Design Code for Aged Facilities". Xinjiang province is located in the northwest China, and the regional economic development is seriously lagging behind. In 1997, the state made a major decision to balance the development of the east and the west and deployed a "matching aid to Xinjiang". It has been 20 years since. Since the 18th National Congress of the Communist Party of China, it has clearly stated that counterpart aid is a national strategy and proposes a new round of counterpart support work. Aid provinces and cities continue to deepen the work of people's livelihood and aiding Xinjiang province [6]. Xinjiang province seized the opportunity of "Counter-Aid to Xinjiang" and give full play to the positive role of the provinces and cities in Xinjiang. New or renovated public welfare institutions were built, and the construction of houses was similar to the mainland. The facilities and equipment were well-equipped and the environment was good. Two of the public pension institutions were all full-scale aid projects in Zhejiang Province. However, only one public pension institution has a medical office, a treatment room and a rehabilitation room, and deploys doctors and nurses with well-defined functions. It is equipped with basic medical rehabilitation equipment such as disinfection equipment, first-aid equipment, electrocardiogram, oxygen cylinders. One public pension institution has only one treatment room and a doctor can make simple medical activities. The medical equipment provided by the five pension institutions are only sphygmomanometers. The configuration of medical facilities and equipment is seriously inadequate, and the shortage of medical staff, which is consistent with the results of some scholars [7], [8]. It can be seen that the public pension institutions in Xinjiang Province are unable to provide services that meet the needs of medical care for the elderly, and the combination of medical care and old-age care services is seriously inadequate. At present, the main service provider in the pension institution is the caregiver. It is found that caregiver is generally able to understand the basic situation of the elderly and provide them with good basic life care, but there are problems of too old age, low academic qualifications and insufficient allocation with them. And due to the lack of professional knowledge, it is difficult for them to complete the technical difficulty and the need for better comprehensive quality, which is consistent with Wang Jing [9]. Coupled with the lack of professional and technical personnel such as psychologists and social workers, the elderly are more satisfied with life care services than mental entertainment services.

\section{B. Analysis of the Factors Affecting the Service Quality of Public Pension Agencies in Xinjiang}

Most studies [10], [11] show that there is a certain relationship between the level of satisfaction with the quality of service for the elderly and the sociological factors such as gender, age, education level and marital status. This study shows that the service quality satisfaction of Uygur elderly people is higher than that of Han elderly people. Field research and interviews have found that this has a greater correlation with the provision of cultural care by the pension institutions in ethnic minority areas. Multicultural nursing proposes that nursing staff adopt different nursing methods according to the world outlook, values, religious beliefs and living habits of different nursing objects to meet the needs of health care in different contexts [12]. The public pension institutions located in ethnic areas respect the national cultural customs of the elderly when providing life care and the manager pays attention to building a cultural environment with ethnic characteristics. For example, some public pension institutions in this survey allow the elderly to take time off every Saturday, which go to the local characteristic market, named as Toksun Bazar. They also distribute national costumes for the elderly, set up an activity room full of ethnic characteristics, and regularly broadcast the music of Macy's music every day. The care service with national culture has deepened the sense of belonging of the elderly and helped them adapt to the cultural environment of the pension institutions in the ethnic areas, thereby improving service satisfaction. There is also a difference in the service satisfaction of the elderly in different occupations. The self-employed households have the highest satisfaction of the elderly and the lowest satisfaction of the farmers. The analysis may be that the nature of the work of self-employed households cultivates their optimistic and indifferent personality, and the tolerance for dissatisfaction is high, so that the satisfaction is the highest. The lowest satisfaction of farmers may be that the elderly are worried about the fields and real estate. After staying in the institution, it is easy to cause dissatisfaction and affect satisfaction. The type of the elderly is also one of the influencing factors of service quality satisfaction in this study. The service satisfaction of the elderly in government-funded is lower than that of the self-funded elderly. This difference mainly comes from the public pension institutions that accept the elderly in the society and participate in market competition. The monthly living allowance for the elderly in government-funded elderly is 660 yuan per month in Xinjiang Uygur Autonomous Region. Compared with the per capita consumption expenditure of residents in the current autonomous region, the organization cannot provide services that require certain purchasing power, and some of the elderly's needs are not met. Service quality satisfaction declined.

\section{CONCLUSION}

This study shows that the service environment, life care, medical care and spiritual entertainment of five counties and cities in Xinjiang have a critical impact on the overall quality of the services provided by the public pension institutions. The hardware facilities in the institution are integrated with those in mainland China. The elderly residents have a high degree of satisfaction with the service environment, but a low degree of satisfaction with the elderly service, especially the medical care service. The quality of the elderly service still needs to be significantly improved. The quality of oldage care service is affected by many factors. In this study, insufficient allocation of medical staff, lack of old-age care staff and low quality are the key factors affecting the service quality of public pension institutions in five counties and cities in Xinjiang. Improving the quality of medical care 
services in public pension institutions and actively promoting the combination of medical care and old-age care will be the challenges faced by public pension institutions in five counties and cities in Xinjiang.

The study further found that different ethnic groups, occupations and different types of elderly people have different perceptions of the quality of service provided by public pension institutions, which will affect the evaluation of service quality. It can be seen that the composition of service quality has its subjective factors, which reflect the actual needs and expectations of service users for service quality. It is suggested that when formulating service quality specifications, we must not only consider the external control norms of services, but also consider the diversified needs of the elderly, and build a truly people-oriented service quality evaluation system to guide the healthy development of the aged care service organizations.

\section{ACKNOWLEDGMENT}

All of us Thanks the China Life Care Association Humanities Nursing Committee for funding the project.

\section{REFERENCES}

[1] Liu Xiaozhuang, Chen Yan, Current status and thinking of the research on the quality of institutional aged care services, Health Vocational Education, vol. 03,pp.142-145,2018 .

[2] Pan Lin, Some Thoughts on Promoting the Development of Social Pension Service Industry in Xinjiang, Talent Resources Development, vol. 04 ,pp.31-34, 2018.

[3] Jing Jie, Research on service quality evaluation of private pension institutions based on the perspective of the elderly, Hebei University of Economics and Business, 2012.

[4] Wang Lijian, Feng Yan, Wang Cheng, Research on Service Quality Evaluation of Aged Aged Organizations, Population and Development, vol. 06, pp.96-102,2017.

[5] Hu Junjiang, Investigation on resource allocation of old-age care institutions and countermeasures, Hangzhou Normal University, 2016.

[6] Wang Xiaotong, Chen Changbing, Zhang Na, Research on the Evaluation of the Policy Effect of the New Round of Aid to Xinjiang, Xinjiang Land Reclamation Economy, vol. 12, pp.35-42, 2018.

[7] Zhou Xiaoli, Jiao Yanhui, Wang Chong, Problems and countermeasures in the medical care combined service system of Xi'an old-age care institutions, Chinese Gerontology, vol. 05, pp.1210-1213, 2019.

[8] Wang Ying, Zhang Bao, Cheng Shudong, Zhang Huijun, Wang Huan, Factors influencing the life satisfaction of the elderly in the old-age care institutions in poverty-stricken areas, Chinese Journal of Public Health, vol. 01, pp.132-135, 2017.

[9] Wang Jing, The current status of non-profit pension institutions in Shanghai Xuhui District and the quality of life of the elderly, Fudan University, 2013.

[10] Wang Chengshuang, Yang Yang, Xiao Qi, Dai Ling, Peng Chaohua, Zeng Tieying. Investigation on the experience and influencing factors of elderly people living in nursing institutions, Journal of Nursing Science, vol. 21, pp.87-89, 2018 .

[11] Li Juan, Service Quality of Urban Elderly Care Agencies in Nanjing and Its Influencing Factors, Chinese Journal of Gerontology, vol.19, pp. 4820-4822, 2013.

[12] Li Yan, Wang Yongqiong, Luo Qi, Wang Anqi, Yu Hua, Application status of cross-cultural nursing theory, Integrated Chinese and Western Medicine Nursing (Chinese and English), vol. 02, pp.222$224,2019$. 